DOI: https://doi.org/10.24297/ijct.v19i0.8161

\title{
Technological Approaches in Applied Social learning
}

(Formulate in lieu of industry 4.0)

P.Amuthalakshmi

Madras School of Social Work, Egmore, Chennai - 600 008, India

drarmoise2341971@gmail.com

K.Umachandran,

NELCAST Ltd., 159, TTK Road, Alwarpet, Chennai - 600018, India, umachandran_k@hotmail.com

T.Roosefert Mohan,

Research Scholar, SRM University, Kattankulathur - 603 203, Kancheepuram, India,

roosefert@gmail.com

\begin{abstract}
:
Industry 4.0 covers the readiness of achieving expertise that impacts the society, strategy, talent and technology. Individual, social and economic demands pose ever-changing challenges for education and training even in today's world. In spite of the shrinking rapidity, which progressively affects the cognitive, biological, and information offerings into the new insights on people learning, for an effective reformation to an even more miniature of scientific and technological connect, ultimately on the knowledge content. Today's students will compete in a technological, diverse, multi-cultural world and must be prepared to thrive in that futuristic environment; therefore, it is vital that today's pedagogy produce lifelong learners, who can succeed in a global arena. To ensure our educational technology progresses at the rate demanded by today's ubiquitous digital learners, we are reviewing emerging technologies and traditional teaching methods and propose desirable changes. Further enhancement in student learning and outcomes through technology enabled learning builds alliances among institutional units, employers, community partners and provides the effective delivery of learning services and opportunities to students. Technology depends on the cleverness and the innovative application of theoretical tools from control and estimation for scalability through hierarchy and multi-modality. Educational technology enhances the learning experience for students, faculty, the university and community at large. Hence, to develop a richer context for student learning, covering societal inadequacies, injustices in empowerment to learning access among students, cross-cultural involvements, and opportunity to learn, we deliberate on the latest trends in pedagogy - intelligent tutoring systems and ICT integration that can be modified during their implementation to suit future needs for industry 4.0 requirements.
\end{abstract}

\section{Key words}

Industry 4.0, internet of things, smart teaching, learning, future skills, robotics

\section{Introduction:}

Today's students are the most diverse and technologically-advanced generation of students to ever enter our classrooms (Helen Soule et al., 2015). In the past decades, computers have served to overcome the difference across countries and cultures, getting improved equity in education. Instructive utilities like multimedia and video lectures have helped students learn in a multimodal elegance (Qingsong, 2012). These aids have 
facilitated fast-tracked students and conventional pupils in the same way. Fast-tracked students could learn innovative concepts using such learning supports, whereas traditional students could absorb at their individual speed. With the introduction of multimedia, knowledge from various parts of the biosphere became commonly available to any student who had access to computers or multimedia players (Khan, 2010). With the improvements in computer aided manufacturing, the cost of computers decked down rapidly and more people had opportunity to multimedia-based education (Saettler, 1988). While they had numerous benefits, quite a few aspects of learning and long term remembrance can be accomplished by frequent buttressing of values, relationship with compatible individuals, and continuously perplexing learners to realize progressively difficult tasks (Geisinger \& Raman, 2013). Information and communication technologies (ICT) alongside the internet has unfastened various possibilities for learning and education, in particular to those excluded from, and left behind by, traditional education practices. Lifelong learning systems strive to enable all learners to use these technologies for learning and self-empowerment (UNESCO., 2013). To this end, the application of computer technology for education has now matured into fields such as social media, including YouTube video-based learning (e.g., Youtube) and evaluation systems (Krishnan, 2017). In this work, we highlight recent advances in educational technology that exemplify open innovations in the field of educational research. To this regard industry in the global economy and high-speed broadband infrastructure demand a workforce that can keep pace with unprecedented technological advances, thus the industry 4.0 is an equalizer that will provide more access to education, jobs and financing across different geographies and social groups. Novel technologies will demand different skills and would impact jobs which potentially lead to income disparity and uncertainty. The critical elements of an educational enterprise connects teaching, learning, assessment, accountability, leadership, culture and infrastructure through technology-broadband, devices, digital content (Helen Soule et al., 2015). Technology enabled learning has revolutionized the way we interconnect with our personal links of friends and family, and has forever changed the way we involve with and acquire new knowledge and information.

\section{Online Assignment Submission}

In order to promote quality education from focus away from teaching towards learning, must be facilitated with a move from a teacher-centered approaches to learner-centered activity based learning, where in addition to the mere acquisition of information and knowledge, the development of transversal skills and competences for application based learning can be facilitated. Harnessing the power of today's Learning Management Systems includes online assignment submission such as written essays, e-portfolios, and other types of assignments that can be viewed asynchronously by the teacher. As the teacher must facilitate learning experiences that are grounded in the real world and make effective use of technology, they also have the flexibility of grading these assignments with comments and suggestions later as well as enjoy the following benefits for online assignment submission. Thus through this learning happens to encourage higher order thinking, flexibility, creativity and expert use of technologies. Students are able to access their writing at a later date, without the need to scramble through loads of paper (Cavus \& Alhih, 2014). Hence to instill creativity, innovation, communication, collaboration, critical thinking, teamwork, decision making, research fluency, and problem solving, assignments should be directed to be original in application of the globally available online content (Helen Soule et al., 2015). Also having an access to assignments to be relooked into at a later date with teacher's comments helps the students reflect more deeply on their work. With ubiquitous electronic devices available today, they are able to view their work from their phones and tablets, whether they are home or on travel (Hrastinski, 2008), and Students are able to upload video projects reflecting their work, so they take considerable interest and initiative doing the work. Peer groups of students are able to easily view their peers' work in video format, so they are able to exchange knowledge, ideas, and expressions that promote cross-cultural understanding. This facilitates the value of more structured and formal knowledge acquisition, approached through innovative, ingenious, adaptable social technology via fitment of our needs.

\section{Cross-Cultural Technology Integration}

Industry 4.0 preparation challenges all strongly-held views, established practices, institutional power and traditional conceptions of knowledge and conceptions of education and learning should be organized. The 
rapid advancement in technology has moved education beyond the walls of the classroom, allowing institutions to extend their reach to students globally. Most of this advancement is fuelled by the Internet and emerging technologies such as cloud computing, mobile apps, social media, and open- source learning management software, free online ICT tools and educational resources. Industry 4.0 would involve very high level of Computational intelligence with timely fusion and analysis of big data, acquired from IoT and other source would play a key role in this challenge (Alam, Mehmood, Katib, Albogami, Albeshri, \& Krishnan, 2017). Teaching, learning, and researching are now ubiquitous, occurring anywhere and anytime. Consequently, classrooms, whether for F2F, online, or blended courses are now more culturally diverse, requiring educators to accommodate for such diversity in making student learning more meaningful and potentially successful (Ferdinand-James, 2017). In addition, blending technology into our daily lives has become mainstream with students bringing their own devices (BYOD) that increasingly include smart phones and tablets. For deeper understanding of the complexity of social issues and increased sense of connection in the community the use of smart phones has increasingly become efficient, enabling access to information via expanding technology networks assisting students to acquire information within a short time spans and expedites multitask. In integrating these emerging technologies into teaching and learning, 21st Century educators must be mindful of cross-cultural factors (e.g., race/ethnicity, language/communication patterns, values, geographic location, and religious beliefs) that impact their programme content (Gay, 2002) and, by extension, using technology to deliver such content. Social learning perspective is a contextual process, with cognitive engagement and interaction along with common experiences for attaining innovative knowledge and skills in the surviving environment, by performing an active role in sharing and acquiring knowledge and insights.

Overlooking students' culturally diverse backgrounds in the curriculum content can result in students experiencing cultural and intellectual bondage that do not allow them to master such content or prepare them for the global village in which we now live (Hogan, 2011). As such, educators should be culturally sensitive in choosing graphics, colors, videos, podcasts, and websites, reading materials etc. that would accommodate for the equitable representations of students cross-cultural backgrounds(Ferdinand-James \& Umachandran, 2016). The respect for individuality and diversity represents a main principle that has to lead to the elimination of any standard type of learning. (Elena Dănescu., 2015). When interacting with students online, they should also be tolerant of the differences in students' language and communication patterns and provide recordings of lecturers for future review. Faculty should focus on key content (e.g., principles, concepts, theories, and skills) in their delivery while providing students with learning opportunities to think critically about this content such as in using asynchronous debates (Bowen and Watson., 2017). Their lessons and presentation of course content should cater to the increase use of mobile devices by digital natives in learning spaces. For example, the famous PowerPoints used to present lectures and administering of online quizzes should be more concise with shorter bullet points in accommodating the smaller screens on these devices. To overcome the shortcomings of digital divide, providing more opportunities to be engaged at anywhere anytime by leveraging the assets of the community infrastructure to support outside-of-school learning, will facilitate more learning activity. Technology is fundamental to implementing change and the learning strategy should seek to provide learners with opportunities to learn across the full range of their experiences.

\section{Social Networks for Learning}

There are several social network apps followed by more than 7 billion users. Facebook is the most popular of them all, recording about 1.6 billion users a month. WhatsApp is next, recording about 1 billion users a month. Many other social network platforms such as QQ ( 800 million users), WeChat ( 700 million users), and Qzone ( 600 million users) connect the world, bridging gaps between cultures. Increased self-esteem and confidence, impacts personal responsibility thereby affects the sense of personal efficacy. Therefore developing interpersonal skills, tolerance / support for diversity, engagement through volunteer activities provides a vital indication of future community participation (Mundy Meghan., Eyler, Janet., (2002). Thus as a reflective thinking towards providing such opportunity along with the prospects abound for harnessing the online connections for education and learning is best seen in social networks. Social networks can be used for exchanging knowledge, information, and ideas almost instantly. Lectures and webinars can be broadcast with ease of access. Unlike a telephone conversation or video conferencing, many people can listen to a lecture or 
webinar instantaneously. Social networks help to maintain communication between teachers and students, making two way communications a reality. This affordance is great for education and knowledge transfer as feedback and correction can be provided quickly, improving knowledge retention(Greenhow, 2011). Professional networks like LinkedIn offer opportunities for networking with professors, experts, and businesses. ResearchGate offers opportunities for networking with professors and academicians across the world. Students can use ResearchGate to network with professors working in the field of research they are interested in, and collaborate for future opportunities. Micro blogging platforms such as Twitter lets users 'tweet' their thoughts with a maximum of 140 characters (Chamberlin \& Lehmann, 2011). Industry 4.0 aims to become a result of the continuing digitization where the value creation chain is networked and all of the relevant information can be independently and directly exchanged between the individuals in the chain's link of people, objects and systems are dynamic, real-time-optimized and self-organizing, cross-company value added networks that can be optimized according to cost, availability and resource consumption (Daniel Buhr., 2017). Social network learning covers all segments of peer coaching, feedback, action learning, virtual mentoring and building or proliferating the communities of good practice.

\section{Intelligent Tutoring Systems}

Reflection is the key ingredient for transfer learning, helps students connect content and experiences for a deeper understanding of the subject matter and also offers provides an opportunity to think critically examine their values, beliefs, and opinions. To enable better involved reflection, online multimedia tools facilitate greater coordination in improving the educational process. Many scientific concepts such as rotational motion and three-dimensional dynamics involve stereoscopic thinking. It is not possible to explain these concepts on a two dimensional blackboard. By designing multimedia appropriate to the level of the target audience (students), it was shown that effective learning can be achieved. Recent advances in multimedia authoring tools such as Easy Java Simulations have enabled scientific teachers to make their own simulations or modify existing simulations for classroom use. To be applicable in a classroom, a computer-based tutoring system has to have several requirements for success. The user interface is the first step in student interaction with the computer system, so it has to be designed very carefully. The background and foreground colors of the interface screen should be selected for text clarity. The text font size should also be appropriate (Hong, Chen, Chang, \& Chen, 2007). With all these considerations in mind, and to ensure the tutoring system provides flexibility to the author in designing the interface, Cognitive Tutor Authoring Tools (CTAT), hosted by Carnegie Mellon University, provides a useful platform for hosting intelligent tutors designed by teachers. It offers great flexibility of design, and ease of use. The CTAT- based tutor is created using the HTML programming environment, and implemented on Tutorshop, a freely available platform for deploying CTAT based tutors, also hosted by Carnegie Mellon University (Aleven \& Sewall, 2010). Student-computer interaction data is streamed to Datashop (Koedinger, Baker, Cunningham, Skogsholm, 2010, \& Umachandran et al., 2017), a big data repository for collecting anonymous student data, maintained by Carnegie Mellon University.

\section{ICT and Smart Education}

Information and communication technologies (ICT) are widely recognized as a great influencer in the area of education with a considerable measure through the proficiency in retrieving and processing digital information (Aesaert et al., 2015). While there is a lack of a paradigm that connect the ICT to smart education, the focus is on the technology applications and solutions rather than on the outlying of models for the concept of smart education (Shirazi, Gholami, \& Añón Higón, 2009). Smart education contains a set of tools in delivering educational services and in fostering interactive learning by leveraging digital technologies and content, commonly defined as "phenomenon of the modern e-learning" and is shaped by three dimensions: educational outcomes, ICT and organizational aspects. Literature on the role of ICT in education is huge. The importance of digital support is widely recognized for both students and teachers, even if the use of ICT per se is not sufficient because it requires the contextual implementation of a parallel pedagogic approach (Talebian, Mohammadi, \& Rezvanfar, 2014). Thus, ICT can be a great addition to teaching, but it cannot suffice as a teacher in itself. Particular interest is given to students and, more precisely, to the use of ICT and its connected affordances, critical issues, problem solving and team work perspectives. Some scholars are concerned about 
the aspect of 'self-efficacy' concerning the use of computers and internet. The concept of self-efficacy, which captures the relevance of a particular ICT teaching tool to a specific domain area, depends on many factors, such as gender, individual cognitive ability, and familiarity with topic of interest. So, before using ICT for a specific knowledge domain, all these factors must be considered (Hafkin \& Huyer, 2008).Technology based learning has more uncertainty and variation in student learning outcomes than in traditional courses evaluation, hence the outcome should be properly verified with a viva-voce examination for achieving desired effects, as it may reveal in the discovery of whether someone really understands something or has "learnt it parrot fashion" (Turing., 1950). Social learning exists on the development of nurturing behaviors that encourage collaboration and sharing, in addition its adoption (Anderson., 2018).

\section{Provisioning towards industry 4.0}

Smart technological utilization through engagement, facilitation, and requisite training offers the manufacturing industry with a great potential along with the digital economy to positively transform business and society. The industry 4.0 requirements are to be assisted with precision data analytical tools which integrate advanced robotics, artificial intelligence, 3D printing, and augmented reality extraordinarily escalating the speed of the organization's management and delivery systems to perform taking care of the process complexity, and competencies. However, not to take too much of complications, but for illustrative learning, the following industries such as Foundry (manufacturing), Health (oral products), Food (confectionary), tourism (nature and wild life) and Service (higher education) are elucidated below.

1. Manufacturing: As machine learning perfects language recognition and translation; satisfying the user to boosts its adoption along with neural networking; employees can get instant feedback on process flow, its interruption, and predictive controls.

2. Oral products: Application in health sciences has a good example of human oral wellness. The mouth is an integral part of the body, oral health is an essential component of overall health and quality of life, hence toothpaste market depends on the relative prices, socio-economic status, brand loyalty, and household size as marketing mix variables affect different consumer buying behavior. Continuous surveillance and survey data helps in establishing the trends in oral health (Parisa Ziarati et al., 2018).

3. Confectionary: In Confectionery industries the food technology research studies have found the dough of flat breads is very versatile because it can be obtained from several types of flour, including non-gluten flours, leading to different consistency.

4. Tourism : Application in Wildlife sanctuaries have special compartments or enclosures as well as designed trails for unique species that are mostly replicas of their natural habitats so that species could feel at home true to its core objective, it should not breed or exploit any species for commercial purposes (Dickson., 2019).

5. Educational Services : Application in education illustrate nuances such as Listening, feedback techniques influences relationships, strategies to overcome communication barriers and tolerance of individual or group differences; prevent bullying, violence, and abuse; and encourage peaceful resolution of conflict have a greater impact on relations.

Technology for industry 4.0 depends on the ingenuity and the pioneering application of abstract tools from control and assessment for scalability through hierarchy, multi-modality, synchronization of sensors, projection-position-trajectory motion capture for simultaneous planning with distributed assignment of signals through cooperative mapping of various sub-systems thus providing protection against Collision, accidents and manipulations (Soon-Jo Chung., Aditya Paranjape., Philip Dames., Shaojie Shen., Vijay Kumar., (2019). Further the knowledge in tradition in all types of workplace communications with the documentations through log books and paper communications will become replaced by instant messaging tools. Quality is achieved via access to internal and external technology know-how, and the order is carried out on schedule. 
The automation scenario systems direct humans to monitoring and control tasks which are taken over by technology, thus preparing to distribute information in real time. Employees respond to the needs of cyberphysical systems (CPS) and take on primarily executive tasks (Daniel Buhr., 2017). The manufacturing establishments world continue using digital transformation to optimize their product offering, optimizing resources and improving process utilization with large IT platforms. The manufacturing process would link machines and logistics equipment to automatically get connected to the cloud-based AI systems and decide for optimized performance. Production systems equipped with computer based learning will coordinate the sync of robotic systems to operate with limited human intervention (Mohan., 2019).

\section{Conclusion}

In industry people are process interdependent and therefore careful syncing the requirement for enabling the integrated complex production/service process system in a real economic environment is a vital conjures. Industry 4.0 requires development of learning and decision-making among people in architecting processes that will provide high levels of autonomy and flexibility leading to reduced risk and cost on market flexible autonomous operations. In summary, we have reviewed various important aspects of education that would relate to educational technologies and that can be used to facilitate learning in a cross-cultural context for social learning in industry 4.0. Latest technologies shape the future of education, so it is vital that they are used by teachers from all over the globe. As the world is dwindling in terms of transportation, information, and communication, technology will play an important role in connecting world citizens in a hugely complex network of information. By reviewing state of the art technologies that exist today, we provided an insight into the classroom of the future. We trust this will help teachers and innovators across the globe to harness today's technology for its utmost effectiveness, and catalyze future innovations that bridge gaps and cracks present in taking advantage of the affordances of today's emerging technologies, even though technological experts have recognized the interconnectedness of technology with directional accountability, which in future will prove a employee's should have a very multidisciplinary knowledge and skills, even at entry level into industry.

\section{References:}

1. Aesaert, K., Van Nijlen, D., Vanderlinde, R., Tondeur, J., Devlieger, I., \& Van Braak, J. (2015). The contribution of pupil, classroom and school level characteristics to primary school pupils' ICT competences: A performance-based approach. Computers and Education, 87, 55-69. https://doi.org/10.1016/j.compedu.2015.03.014

2. Alam, F., Mehmood, R., Katib, I., Albogami, N. N., \& Albeshri, A. (2017). Data Fusion and IoT for Smart Ubiquitous Environments: A Survey. IEEE Access. https://doi.org/10.1109/ACCESS.2017.2697839

3. Aleven, V., \& Sewall, J. (2010). Workshop: Hands-on Introduction to Creating Intelligent Tutoring Systems without Programming using the Cognitive Tutor Authoring Tools (CTAT). Icls 2010, 2, 511-512.

4. Antonella Pasqualone., (2017), Flat breads: origin, diffusion and baking methods. New ideas for the market of ethnic, traditional or gluten free breads, TECNICA MOLITORIA, Vol 68., No7, pp.522-540.

5. Bowen, J. A., \& Watson, C. E. (2017). Teaching naked techniques: A practical guide for designing better classrooms, John Wiley \& Sons, Inc. San Francisco, CA.

6. Chamberlin, L., \& Lehmann, K. (2011). Twitter in higher education. ... Technologies in Higher Education, (June), 1-20. https://doi.org/10.1108/S2044-9968(2011)0000001021

7. Daniel Buhr (2017), Social Innovation Policy for Industry 4.0, A PROJECT BY THE FRIEDRICH-EBERTSTIFTUNG2015 AND 2017pp.24.

8. Dickson Adom, Krishnan Umachandran, Daniel Boamah Asante, Parisa Ziarati, Barbara Sawicka., (2019), 
The Concept, State, Roles and Management of Protected Areas in Ghana: A Review, ACTA SCIENTIFIC AGRICULTURE (ISSN: 2581-365X), Vol 3 Issue 1, pp.68-76

9. Elena Dănescu.,(2015), Intercultural Education from the Perspective of Training Didactic Competences, The 6th International Conference Edu World 2014 "Education Facing Contemporary World Issues", 7th 9th November 2014, Procedia - Social and Behavioral Sciences 180 (2015) 537 - 542, ScienceDirect18770428, doi:10.1016/j.sbspro.2015.02.156

10. Ferdinand-James. (2017). Asynchronous Debates - Contribution to Chapter 10. In J. A. Bowen \& E. C. Watson (Eds.), Teaching Naked Techniques: A Practical Guide to Designing Better Classes (1st ed., p. 154). San Francisco, CA.

11. Ferdinand-James, D., \& Umachandran, K. (2016). Online Assessment: Product development in academic writing. Maha Journal of Education, 2(1), 73-78.

12. Gay, G. (2002). Preparing for Culturally Responsive Teaching. Journal of Teacher Education, 53(2), 106116. https://doi.org/10.1177/0022487102053002003

13. Geisinger, B., N., I., \& Raman, D. R. (2013). Why They Leave: Understanding Student Attrition from Engineering Majors. International Journal of Engineering Education, 29(4), 914-925.

14. Greenhow, C. (2011). Online social networks and learning. On the Horizon, 19(1), 4-12. https://doi.org/10.1108/10748121111107663

15. Hafkin, N. J., \& Huyer, S. (2008). Women and Gender in ICT Statistics and Indicators for Development. Information Technologies and International Development, 4(2), 25-41. https://doi.org/10.1162/itid.2008.00006

16. Hogan, R. (2011). Blended Learning across Disciplines. Blended Learning across Disciplines: Models for Implementation. https://doi.org/10.4018/978-1-60960-479-0

17. Hong, C. M., Chen, C. M., Chang, M. H., \& Chen, S. C. (2007). Intelligent web-based tutoring system with personalized learning path guidance. In Proceedings - The 7th IEEE International Conference on Advanced Learning Technologies, ICALT 2007 (pp. 512-516). https://doi.org/10.1109/ICALT.2007.167

18. Helen Soule et al., (2015), Building Your Roadmap to 21st Century Learning Environments, A planning tool for education leaders, pp.195, https://www.roadmap21.org/assets/Creating-Your-Roadmap-to-21stCentury-Learning-Environments1.pdf

19. Hrastinski, S. (2008). Asynchronous and Synchronous E-Learning. Educause Quarterly, 31(4), 51-55. https://doi.org/citeulike-article-id:8060645

20. J. Anderson ., (2018), Social learning: how it works in the workplace, An exploration of the factors that influence, define and nurture modern social learning. Pp.32. https://cdn2.hubspot.net/hubfs/406421/Kineo\%20Global/Guides/social-learning-how-it-works-in-theworkplace-whitepaper-uk.pdf

21. Jossey-Bass.Cavus, N., \& Alhih, M. S. (2014). Learning Management Systems Use in Science Education. Procedia - Social and Behavioral Sciences, 143, 517-520. https://doi.org/10.1016/j.sbspro.2014.07.429.

22. Khan, B. (2010). The Global e-Learning Framework. Stride Handbook 8. Retrieved from http://technologysource.org/article/336/

23. Koedinger, K. R., Baker, R. S. J., Cunningham, K., \& Skogsholm, A. (2010). A Data Repository for the EDM 
community: The PSLC DataShop. Handbook of Educational Data Mining, 43-55. https://doi.org/doi:10.1201/b10274-6

24. Krishnan Umachandran, Debra Sharon Ferdinand (2017), Affordances of Data Science in Agriculture, Manufacturing, and Education, Book - Privacy and Security Policies in Big Data, Edition: 1, Publisher: IGL Global, DOI: 10.4018/978-1-5225-2486-1.ch002.

25. Krishnan Umachandran (2017),Technology in Business education, (Learning Applications - Assignment Submissions in YouTube), 27th International Conference on Teaching, Education and Learning (ICTEL), 1516 Nov 2017, Kuala Lumpur.

26. Krishnan Umachandran, P. Amuthalakshmi, (2017), Interpersonal relationships at workplace, Splint International Journal of Professionals, ISSN 23496045, Vol IV, Issue 6, June 2017.

27. Mundy Meghan., Eyler, Janet., (2002), Service-Learning and Retention: Promising Possibilities, Potential Partnerships. Vanderbilt University. 2002.

28. Parisa Ziarati, Krishnan Umachandran, Dickson Adom, Mohamed A. El-Esawi, Barbara Sawicka (2018), Fluoridex Daily Defense Toothpaste for Oral and Dental Health: A Review, J Med Discov (2018);3(3):jmd18034; DOI:10.24262/jmd.3.3.18034

29. Qingsong, L. (2012). The Application of Multimedia Technology in Web Education. Physics Procedia, 33, 1553-1557. https://doi.org/10.1016/j.phpro.2012.05.252

30. Saettler, P. (1988). History of Educational Technology. The Encyclopaedia of Educational Media Communications and Technology.

31. Shirazi, F., Gholami, R., \& Añón Higón, D. (2009). The impact of information and communication technology (ICT), education and regulation on economic freedom in Islamic Middle Eastern countries. Information \& Management, 46(8), 426-433. https://doi.org/10.1016/j.im.2009.08.003

32. Soon-Jo Chung., Aditya Paranjape., Philip Dames., Shaojie Shen., Vijay Kumar., (2019),

A Survey on Aerial Swarm Robotics, pp.19. https://authors.library.caltech.edu/87925/1/tro-aerialrobotics_final.pdf.

33. Talebian, S., Mohammadi, H. M., \& Rezvanfar, A. (2014). Information and Communication Technology (ICT) in Higher Education: Advantages, Disadvantages, Conveniences and Limitations of Applying Elearning to Agricultural Students in Iran. Procedia - Social and Behavioral Sciences, 152, 300-305. https://doi.org/10.1016/j.sbspro.2014.09.199

34. T. Roosefert Mohan., (2019), Zero Down Time Approach in Smart Factory, Doctoral Committee presentation, SRM University

35. UNESCO., (2013), Lifelong Learning, UNESCO Institute for Lifelong Learning, Technical Note, pp.10.

36. Turing A. M., (1950),Computing Machinery and Intelligence. Mind 49, pp. 433-460, https://www.csee.umbc.edu/courses/471/papers/turing.pdf 